\title{
Thermally Reduced Graphene Oxide: Synthesis, Structural and Electrical Properties
}

\author{
MM Mokhtar ${ }^{1 *}$, SA Abo El Enein ${ }^{2}$, MY Hassaan ${ }^{3}$, MS Morsy' and MH Khalil' \\ ${ }^{1}$ Housing and Building National Research Center (HBRC), Building Physics Institute, Cairo, Egypt \\ ${ }^{2}$ Chemistry Department, Faculty of Science, Ain Shams University, Cairo, Egypt \\ ${ }^{3}$ Physics Department, Faculty of Science, Al Azhar University, Cairo, Egypt
}

\begin{abstract}
This study represents a new technique to synthesize graphenenano sheets, where Graphene Oxide (GO) was synthesized by oxidation of graphite flakes via modified Hummers method. The produced GO was thermally reduced (exfoliated) at $350{ }^{\circ} \mathrm{C}$ for $1,3,6$ and 9 hours to produce graphenenano sheets having different degrees of reduction assigned as R1, R3, R6 and R9. The influence of reduction time on the physical properties of graphene was investigated using X-ray Diffraction (XRD) and Thermal Analysis (TGA) to study the phase composition. The specific surface area was studied using nitrogen adsorption technique at $77.35 \mathrm{~K}$, also Raman spectroscopy as well as FTIR techniques were used to analyze pure graphene sheets. The microstructure was examined using High Resolution Transmission Electron Microscopy (HR-TEM) and finally the electrical conductivity of the four graphene samples was reported. Results revealed that: by increasing the reduction time; GO platelets were well exfoliated to few layers graphene sheets, also the surface area was markedly enhanced and reached about $62 \%$ of GO, as well as an enhancement of about $152 \%$ in conductivity was achieved and a high quality of graphitization was obtained, where $I_{D} / I_{G}$ ratio reached 1.34 in Raman spectra.
\end{abstract}

Keywords

Graphenenanosheets, Thermal reduction, Surface area, Thermal analysis, Raman spectroscopy

\section{Introduction}

Graphene has been attracted the attention of academic and industrial interests because of its exceptional electrical, thermal, electronic, mechanical and high crystal quality characteristics [1]. Graphene also has a zero band gap and characterized as a semimetal [2].

Graphene is one of the carbon allotropes and it is considered to be the basic parent structure of it. These allotropes include graphite, fullerenes, nanorings, nanobuds, as well as single, double and multi-walled carbon nanotubes $[3,4]$. There are three main graphene sheets types: single, bi, and few layers $(<10)$ [5]. Also Graphene is good conducting nanofiller with a two dimensional one atom thick planar sheet of carbon atoms [6].

Graphene can be used as filler material for polymer composites [7], it can be considered as a good electrode for super capacitors because of its high surface area, high electrical conductivity, and good electrochemical stability [8]. Also graphene and graphene oxide are used in cement composite pastes to enhance their mechanical and micro structural properties hence it was found that the addition of $0.03 \mathrm{wt} \%$ of GO can improve the mechanical strengths of cement composites by about $40 \%$ [9], while the incorporation of $0.05 \mathrm{wt} \%$ of GO into cement mortar enhanced the flexural strength by $70.5 \%$ as well

*Corresponding author: MM Mokhtar, Housing and Building National Research Center (HBRC), Building Physics Institute, Cairo, Egypt, E-mail:mmahmoud7@gmail.com

Received: May 19, 2017: Accepted: July 08, 2017: Published: July 10, 2017

Copyright: ( 2017 Mokhtar MM, et al. This is an open-access article distributed under the terms of the Creative Commons Attribution License, which permits unrestricted use, distribution, and reproduction in any medium, provided the original author and source are credited. 
as the compressive strength was increased by $24.4 \%$ [10]. The incorporation of Graphene NanoPlatelet (GNP) by about 2.4 vol\% increases the tensile strength of GNP-cement mortar [11]. The in-situ Reduced Graphene Oxide (rGO) (i.e. 2D graphene sheets) were added to fly ash geo polymeric composite cement to enhance its mechanical properties, where the addition of $0.35 \mathrm{wt} \% \mathrm{rGO}$ yielded an increase in the flexural strength by $134 \%$ [12].

Graphene has the property of piezo resistivity because of its high electrical conductivity and surface area and it was expected to transfer such property to cement composites $[11,13]$. The electrical resistivity of GNP-cement composites was markedly decreased at GNP concentration of 7.5\% [14]. The electrical conductivity of Polystyrene (PS) was enhanced by the addition of Reduced Graphene Oxide (rGO) by about 20 vol\% of rGO where it was reached $135 \mathrm{~S} / \mathrm{m}$, while the thermal conductivity of the composites was increased by about $90 \%$ as the dosage of rGO increased from 0 to $10 \mathrm{vol} \%$ [15].

Graphene based materials can also be used in advanced energy-conversion devices such as solar and fuel cells, and energy-storage devices, including super capacitors and lithium-ion batteries [16].

Several methods were followed to prepare graphene sheets like Chemical Vapor Deposition (CVD) [1], micromechanical exfoliation [17], thermal decomposition [18], arc discharge method, epitaxial growth on $\mathrm{SiC}$, chemical reduction and liquid phase exfoliation [2].

Zhong-li Wang, et al. followed the improved hummer's method to prepare Graphene Oxide (GO) via thermal decomposition technique. In order to prepare graphene, the solid GO sheets were decomposed by heating at $300^{\circ} \mathrm{C}$ for 1 hour at a rate of $2^{\circ} \mathrm{C} / \mathrm{min}$ [19].

While Q. Zheng and J.K. Kim used the mechanical cleavage method to exfoliate graphite flakes into graphene using a scotch tape. Graphene can be easily peeled off from graphite by a scotch tape because of the very weak interlayer van der Waals force in graphite, this method involves transferring of graphene to a $\mathrm{SiO}_{2} / \mathrm{Si}$ substrate and optically identifies it, and the yield of this technique is very low because it is a manual operation [20].

Nils Krane simply heated and cooled down a SiC crystal, leading to the formation of a single or bi-layer graphene on the Si face of the crystal, while few-layer graphene has formed on the $\mathrm{C}$ face [21].

Ming Zhou, et al. have been synthesized graphene via Liquid-phase exfoliation of Tetra Ethyl Ammonium Graphite Intercalation Compound (TEA-GIC) [22].

It was reported that the chemical Vapor Deposition technique is based on the carbon saturation of a transition metal like [ $\mathrm{Ni}, \mathrm{Pd}, \mathrm{Ru}, \mathrm{Ir}$ and $\mathrm{Cu}$ ] on exposure to a hydrocarbon gas like methane $\left(\mathrm{CH}_{4}\right)$, ethylene $\left(\mathrm{C}_{2} \mathrm{H}_{4}\right)$, acetylene $\left(\mathrm{C}_{2} \mathrm{H}_{2}\right)$ and benzene $\left(\mathrm{C}_{6} \mathrm{H}_{6}\right)$, the number of the obtained graphene layers depends on the hydrocarbon type and the reaction conditions [23-26].

It was also stated that Graphene can be prepared through arc discharge technique, in this method two to three layers Graphene sheets have prepared in $\mathrm{H}_{2}$ atmosphere. The obtained sheets having sizes of 100-200 nm $[27,28]$.

In this study GO was prepared via improved hummers method. We aimed to shed light on the influence of thermal reduction time on the physical properties of graphene.

\section{Experimental Program}

\section{Materials used}

Raw Graphite flakes, $\mathrm{H}_{2} \mathrm{SO}_{4}(98 \%), \mathrm{NaNO}_{3}, \mathrm{H}_{2} \mathrm{O}_{2}$ (30\%) and $\mathrm{KMnO}_{4}(98 \%)$, finally HCL (33\%) and distillated water were used for the washing process.

\section{Preparation of Graphene Oxide (GO)}

GO was synthesized following the improved Hummer's technique [17]. Briefly, graphite $(1 \mathrm{~g})$ was added with $\mathrm{NaNO}_{3}(0.5 \mathrm{~g})$ in a flask, $50 \mathrm{ml}$ of $\mathrm{H}_{2} \mathrm{SO}_{4}(98 \%)$ was then added to the flask under constant stirring at $5{ }^{\circ} \mathrm{C}$ for 1 hour, after that $3 \mathrm{~g}$ of $\mathrm{KMnO}_{4}$ were gradually added ( $1 \mathrm{~g}$ every $15 \mathrm{~min})$. Dilute the solution by slowly adding $100 \mathrm{ml}$ warm distilled water. In this step do not allow the temperature of the solution to increase over about $20^{\circ} \mathrm{C}$ in order to prevent overheating and explosion. Then an aqueous solution of $\left[\mathrm{H}_{2} \mathrm{O}_{2}(3 \mathrm{ml})+\right.$ distilled water $(100$ $\mathrm{ml})]$ was added to the mixture in the flask to be sure that all $\mathrm{KMnO}_{4}$ is completely reacted. After that the mixture was successively washed with HCL and water, and then filtrate the mixture and dry to get the final powder (GO), as described in our previous work [29].

\section{Reduction of GO}

Finally, the prepared GO was divided into 4 samples, each division were reduced at a fixed temperature of 350 ${ }^{\circ} \mathrm{C}$ for different times; $1,3,6$ and 9 hours in air with a heating rate of $10^{\circ} \mathrm{C} / \mathrm{min}$, the resulted graphene samples were assigned as R1, R3, R6 and R9 respectively. By this step we obtained graphene sheets that are ready for characterization.

Where R: refers to reduction while the numbers 1,3 , 6 and 9 refers to the reduction time at $350^{\circ} \mathrm{C}$.

\section{Characterization Techniques}

\section{High-Resolution Transmission Electron Micro- scope (HR-TEM)}

The samples morphology was examined using a High- 


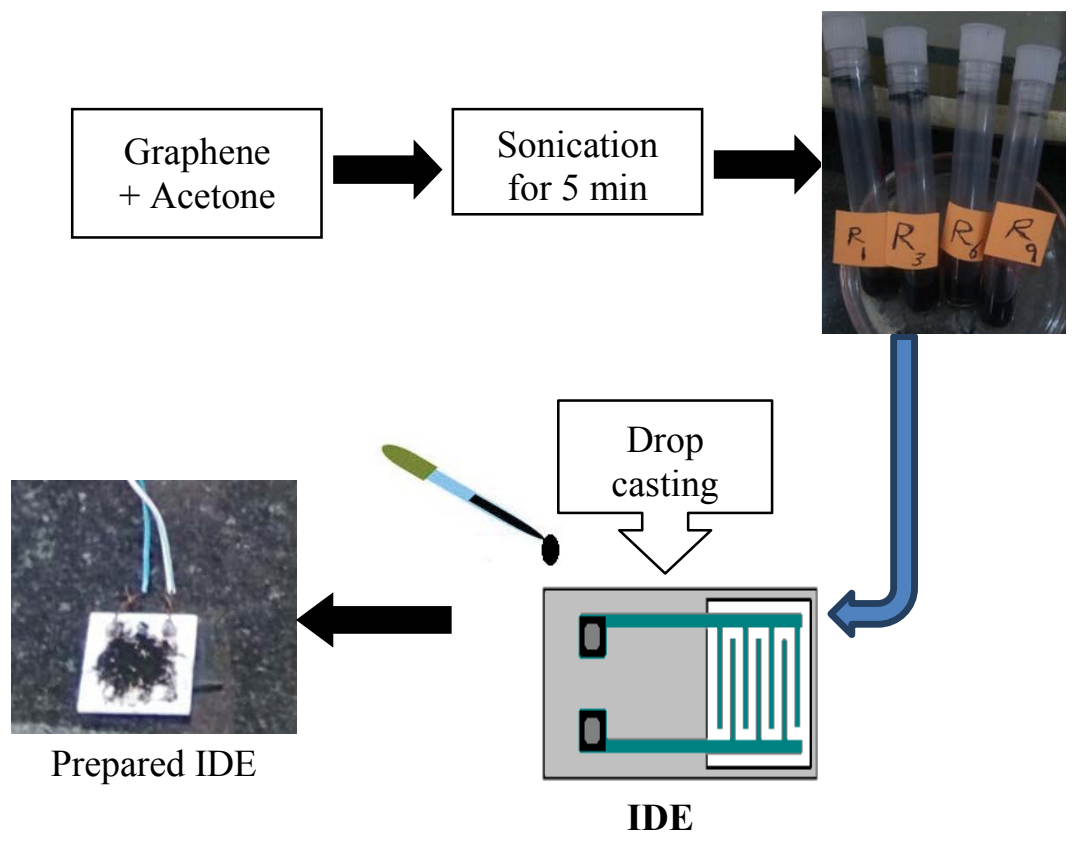

Figure 1: Procedure of sensor preparation.

Resolution Transmission Electron Microscope (HR-TEM, FEI Philips Tecnai G2 S-Twin operated at $200 \mathrm{keV}$ ).

\section{X-Ray Diffraction (XRD)}

The XRD analysis was performed using X-ray diffractometer (Philips PW3050/60) with a $\mathrm{Cu}-\mathrm{Ka} \mathrm{X}$-ray source.

\section{Thermal analysis}

Thermogravimetric analyses of the samples were conducted using a DSC-TGA thermal analyzer (STD-Q600, USA) instrument from $25^{\circ} \mathrm{C}$ up to $800^{\circ} \mathrm{C}$ at a heating rate of $10^{\circ} \mathrm{C} / \mathrm{min}$ in nitrogen atmosphere.

\section{Fourier Transform Infrared Spectrometry (FTIR)}

Bonding characteristics of the samples were analyzed using Jasco-6100 Fourier transformed infrared spectrometer (FTIR; Varian model Excalibur FTS 3000MX, Paolo Alto, CA). The wave number was ranging from 400 to $4000 \mathrm{~cm}^{-1}$.

\section{Raman spectroscopy}

Raman spectroscopy (SENTERRA-Bruker, Germany) with laser source (Nd:YAG) at wavelength of $532 \mathrm{~nm}$ was also used to analyze the samples.

\section{Specific surface area}

The specific surface area of the samples were calculated by using Brunauer-Emmett-Teller (BET) method and the Nitrogen adsorption/desorption isotherms were measured for GO and graphene samples at $77.35 \mathrm{~K}$ on a NOVA 2000e (Quanta chrome, USA).

\section{Electrical conductivity}

- The I-V characteristic curves of R1, R3, R6 and R9 samples were obtained through the following steps:

- A sensor device consisted of gold Inter Digitated Microelectrodes (IDE) with spacing of $5 \mu \mathrm{m}$ and 13 pairs of arms sputtered on ceramic substrate were prepared.

- $20 \mathrm{mg}$ of each graphene sample was suspended in 1 $\mathrm{ml}$ of acetone with ultrasonic process (power of 250 watt and frequency of $20 \mathrm{KHz}$, for $5 \mathrm{~min}$ ).

- $20 \mu \mathrm{l}$ of the prepared suspension was poured on the surface of IDE using micropipette, after few minutes acetone was volatilized and a layer of graphene settled on the sensor. As shown in Figure 1.

- DC power supply (Ztiaoxin, RXN-305D) was used to apply a voltage of $(0.1)-(0.6) \mathrm{V}$ and of $(-0.1)-(-0.6)$ across the IDE's terminals and the corresponding current was measured by a keithely 6485 Pico ammeter for the resistance calculations [30].

The I-V curves were plotted and the slopes were calculated, hence the slope of each curve represents the conductance (in Siemens) of its sample which can be calculated through the following equation:

$$
\mathrm{C}=\frac{1}{\mathrm{R}}=\frac{1}{\mathrm{~V}}
$$

Where; $\mathbf{C}$ is the Electric Conductance $(\mathrm{S}), \mathbf{R}$ is the Electric Resistance $(\Omega)$, I is the Electric Current through the object $(\mathrm{A})$ and $\mathbf{V}$ is the Voltage across the object $(\mathrm{V})$. 


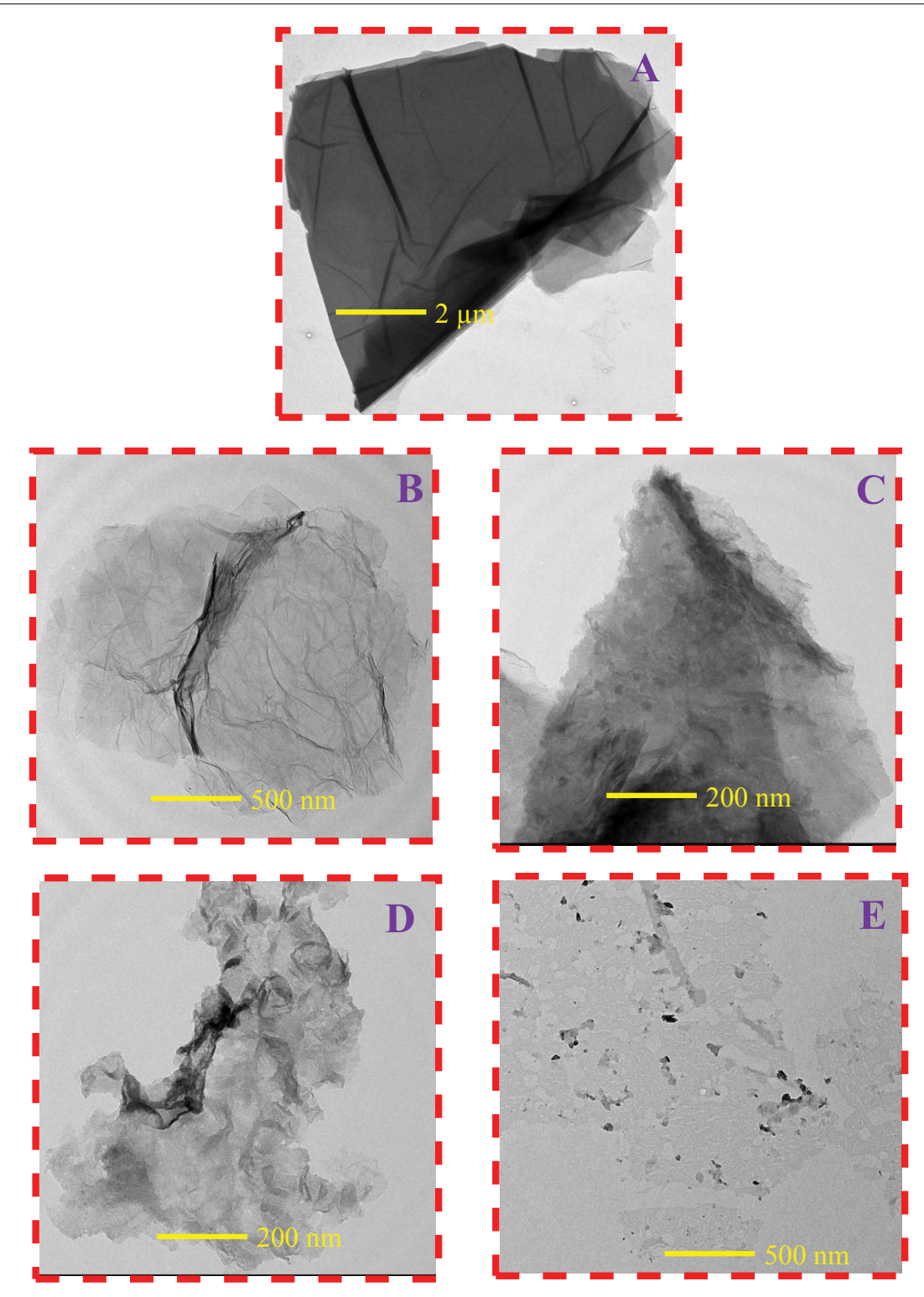

Figure 2: HR-TEM of the different samples A) GO; B) R1; C) R3; D) R6 and E) R9.

\section{Results and Discussion}

\section{HR-TEM}

Figure 2 shows TEM images taken for GO reduced graphene. The obtained material was examined by HRTEM to confirm the formation of GO and reduced graphene to investigate their morphology. The HR-TEM images presented in Figure 2A which represents GO, displayed the formation of transparent particles consisting of multi-layer stacked/non-exfoliated thin sheets. While TEM images (Figure 2B, Figure 2C, Figure 2D and Figure $2 \mathrm{E}$ ) that represents $\mathrm{GO}$ reduced for different times displayed the formation of graphene platelet from few layers to a single layer (Figure 2E). It can also be clearly seen that the reduced graphene samples show a crippled and wrinkled structure; this structure inhibits the restacking of the graphene sheets together.

We also can conclude the effect of reduction time on the morphology and structure of graphene, hence, GO was well exfoliated and reduced to graphene, as the reduction time increased to 9 hours we obtained almost a single layer and ruptured structure of graphene sheet. The wrinkle appearance of Graphene sheets was explained by the high aspect ratio (i.e.) graphene sheet has several hundred nanometers of length compared to just several nanometers of thickness [31].

\section{X-Ray Diffraction (XRD)}

Figure 3 Shows the XRD patterns of graphite, Graphene Oxide (GO), and reduced graphene oxide (R1, R3, R6 \& R9). From the pattern, the peak characterizing graphite was located at $2 \theta=26.4$ with a d-spacing value of 3.37 $\AA$ which is in well agreement with the graphitic nature of carbon, upon chemical oxidation GO was synthesized and its position was shifted to $2 \theta=9.7$ which means that graphite was completely oxidized to GO with d-spacing 


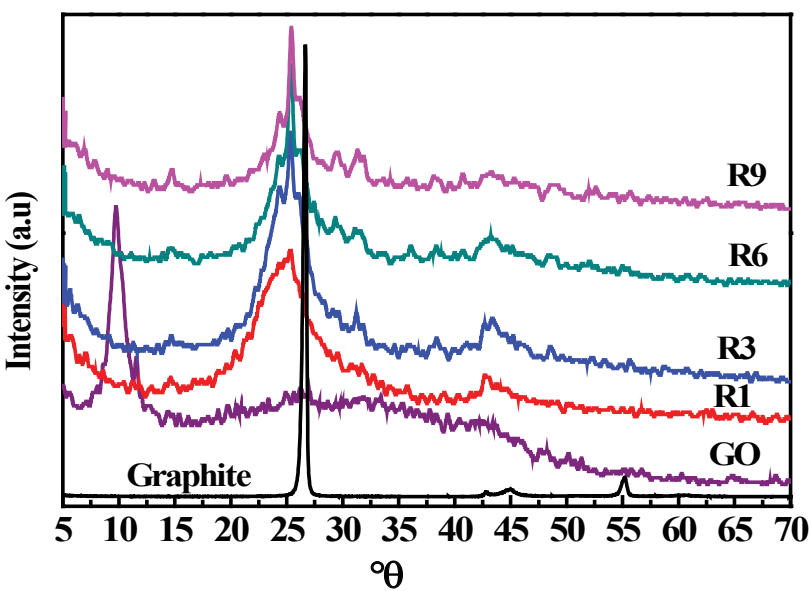

Figure 3: XRD patterns of graphite, graphene oxide and graphene samples.

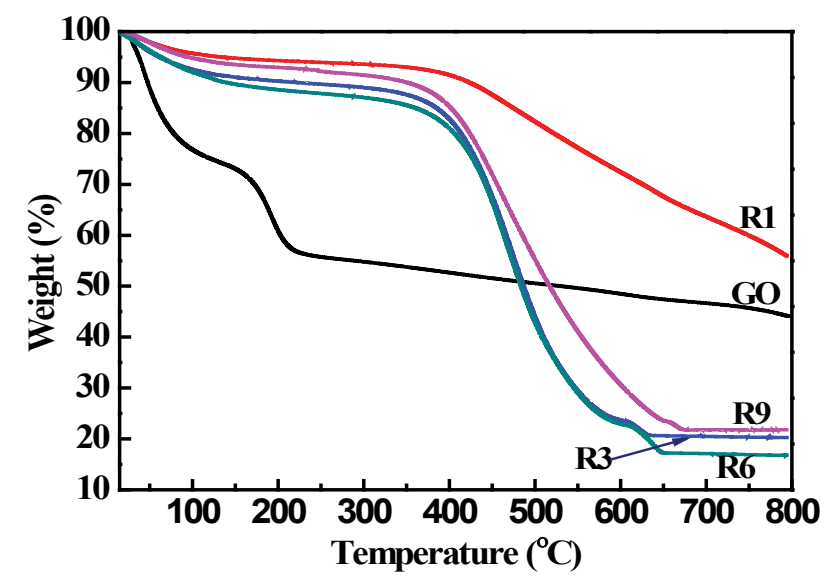

Figure 4: TGA thermo grams of GO and graphene samples.

value of $9.08 \AA$, the increased d-spacing of GO over that of graphite can be attributed to the effect of the introduced oxygen function groups on the edge of each layer. After thermal reduction of GO; the XRD display a peak at $2 \theta=25.3$ for graphene (R) samples which confirms that GO was highly reduced to graphene with the absence of graphene oxide peak, also the interlayer spacing of graphene was $3.51 \AA$ that was very close to that of graphite $[32,33]$. Also it can be observed that, as the reduction time increased the peaks gets sharper and hence closer to the graphite nature.

\section{Thermo Gravimetric Analysis (TGA)}

TGA was used to estimate the thermal stability of our prepared samples. TGA curves of GO and different reduced graphene oxide samples at different times R1, R3, R6 and R9 are presented in Figure 4.

TGA curves showed that the total weight loss of GO was about $56.01 \%$. The loss of weight up to $100{ }^{\circ} \mathrm{C}$ can be attributed to the evaporation of the moisture content and interstitial water, while the loss from $100-250{ }^{\circ} \mathrm{C}$ originated from the decomposition of the acidic func-

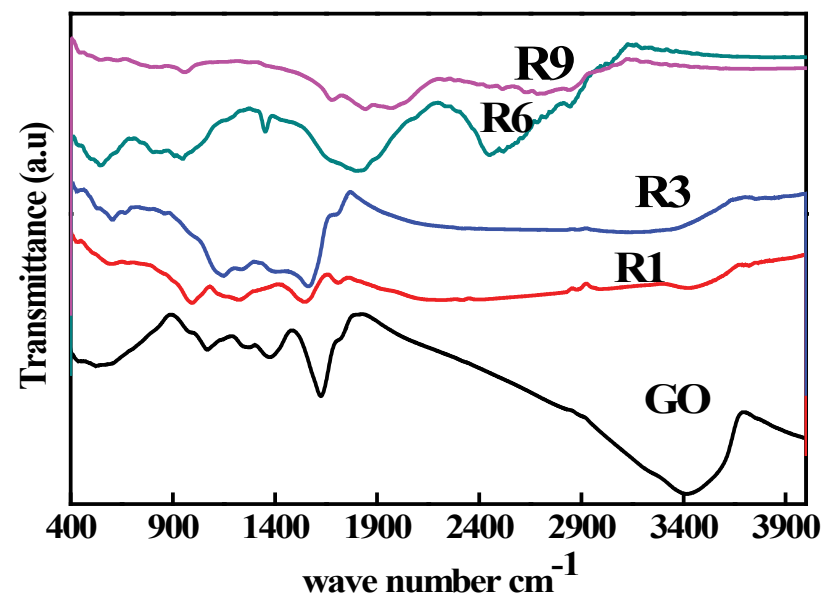

Figure 5: FTIR spectra of GO and graphene samples.

tional groups and hydroxyl groups, hence GO was highly oxidized during the preparation procedure that involved a strong acid treatment and usage of $\mathrm{H}_{2} \mathrm{O}_{2}$ as an oxidizing agent [34], finally the loss up to $800^{\circ} \mathrm{C}$ resulted from the decomposition of carbonyl groups that was formed on the surface of GO during the oxidation process [35].

Regarding the reduced graphene oxide samples, firstly the TGA curve for R1 sample has the same behavior like the graphene oxide reduced by microwave [8] with a total mass loss of about (44.11\%). While, the total weight loss of R3, R6 and R9 reached about 79.74, 83.12 and $78.22 \%$ respectively. The loss up to $100{ }^{\circ} \mathrm{C}$ refers to the loss of adsorbed water, while the loss up to $400{ }^{\circ} \mathrm{C}$ arose from the decomposition of the residual hydroxyl and carboxyl function groups and the loss up to $800^{\circ} \mathrm{C}$ can be related to the loss of the remained carbonyl groups [36].

The curve of R1 shows the highest thermal stability among GO and other R samples. The effect of increasing reduction time appeared in increasing the amorphous carbon species which confirmed by Raman analysis and HR-TEM images.

\section{Fourier Transform Infrared Spectrometry (FTIR)}

Figure 5 presents the FTIR spectra of GO and thermally reduced GO, respectively. When graphite was oxidized many oxygen functional groups were introduced in the structure of GO which has a broad peak at about $3421 \mathrm{~cm}^{-1}$ represents stretching vibrations of $(-\mathrm{OH})$ that resulted from adsorbed water, as well as a peak approximately at $1735 \mathrm{~cm}^{-1}$ due to $(\mathrm{C}=\mathrm{O})$ stretching of carboxyl and carbonyl groups, also the peak at $1621 \mathrm{~cm}^{-1}$ referred to vibrations of $(\mathrm{C}=\mathrm{C})$ groups, also a peak at about 1378 $\mathrm{cm}^{-1}$ was appeared which is referred to $\mathrm{O}-\mathrm{H}$ deformation of $\mathrm{C}-\mathrm{OH}$ group. Finally, the peak appeared approximately at $1081 \mathrm{~cm}^{-1}$ represents the vibration of $(\mathrm{C}-\mathrm{O})$ bond [37]. 
After thermal reduction of GO and with increasing the reduction time, most of the absorption peaks are weakened or disappeared, hence the spectra of R1 and R3 samples showed small peaks for $(-\mathrm{OH})$ between 3450 and $3403 \mathrm{~cm}^{-1}$ due to deoxygenation as a result of reduction process, while for R6 and R9 the peaks for $(-\mathrm{OH})$ was disappeared. However stretching vibrations from $(\mathrm{C}$ $=\mathrm{O})$ still present in R1 and R3 spectra that referred to the presence of carbonyl groups and disappeared in R6 and R9 spectra. Finally, the increased of reduction time led to the appearance of new modes specially for R6 at 550 and $1800 \mathrm{~cm}^{-1}$ that can be attributed to the $\mathrm{C}-\mathrm{H}$ bending mode and aromatic $\mathrm{C}=\mathrm{C}$ stretching respectively [38].

\section{Raman spectroscopy}

Raman spectra of carbon nanomaterials exhibit two main characteristic bands appear between 1200 and 1700 $\mathrm{cm}^{-1}$. In this study, the first band appeared at about 1583.5, $1602.5,1591,1591,1584$ and $1577.5 \mathrm{~cm}^{-1}$ for graphite, GO, R1, R3, R6 and R9 respectively, corresponds to the graphite mode ( $G$ band) which reflects the $\mathrm{sp}^{2}$ carbon atoms, while the second band appeared approximately at $1354.5,1360.5,1365.5,1357,1355$ and $1349 \mathrm{~cm}^{-1}$ for graphite, GO, R1, R3, R6 and R9, respectively, attributes to diamondoid mode ( $\mathrm{D}$ band) is related to the disorder that may arise from certain defects in the structure and amorphous carbon species [39,40].

Upon chemical oxidation of graphite to GO, it was observed that $\mathrm{G}$ band of GO goes broaden more than that of graphite and the intensity of D band of GO was increased over than D band of graphite, this can be explained by the decrease in size of the $\mathrm{sp}^{2}$ carbon in crystalline domain by the creation of defects, vacancies, and distortions during oxidation $[40,41]$.

The intensity ratio of $G$ to $D$ bands gives an indication to the quality of graphitization. From Figure 6 it can be noticed that the band intensity ratio $\left(\mathrm{I}_{\mathrm{D}} / \mathrm{I}_{\mathrm{G}}\right)$ increased from 0.18 for graphite to be 1.08 for GO, which could be attributed to the increase of disordered structure resulted from oxygen functional groups produced during

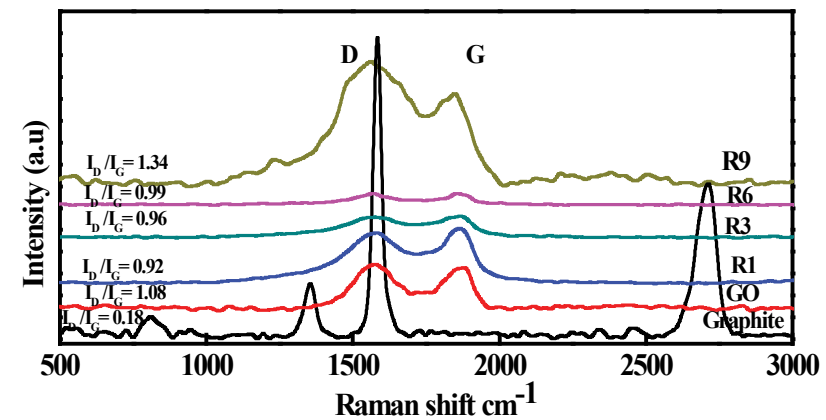

Figure 6: Raman spectroscopy of graphite, GO and graphene samples. oxidation process of graphite.

It can be also noticed that the band intensity ratios $\left(\mathrm{I}_{\mathrm{D}} / \mathrm{I}_{\mathrm{G}}\right)$ for R1, R3 and R6 were 0.92, 0.96 and 0.99 respectively, which is slightly lower than 1.08 for GO and caused by the repair of defects by recovery of the aromatic structure of graphite lattice $[8,32]$. Finally, the spectrum of $\mathrm{R} 9$ shows a dramatically increase in $\left(\mathrm{I}_{\mathrm{D}} / \mathrm{I}_{\mathrm{G}}\right)$ ratio to reach 1.34 and $\mathrm{D}$ band was greatly broadened that reflects the increase of graphitization with a large quantity of structural defects which confirmed by TEM analysis (Figure 2E).

\section{Specific surface area}

The $\mathrm{N}_{2}$ adsorption/desorption isotherms for $\mathrm{GO}$ and thermally reduced $\mathrm{GO}(\mathrm{R} 1, \mathrm{R} 3, \mathrm{R} 6$ and $\mathrm{R} 9)$ are presented in Figure 7, While, Figure 8 shows the specific surface area of GO and graphene obtained from these isotherms.

The specific surface area of GO and thermally reduced GO samples was calculated using Brunauer-Emmett-Teller (BET) method to be $178.4,213.5,233,283.6$ and $289.5 \mathrm{~m}^{2} / \mathrm{g}$

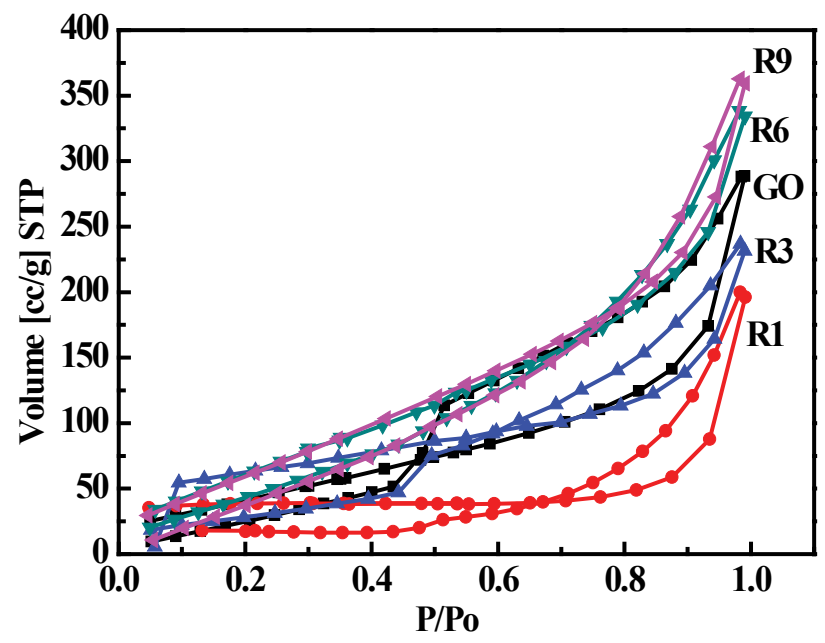

Figure 7: $\mathrm{N}_{2}$ adsorption/desorption isotherms for $\mathrm{GO}, \mathrm{R} 1$, R3, R6 and R9 samples.

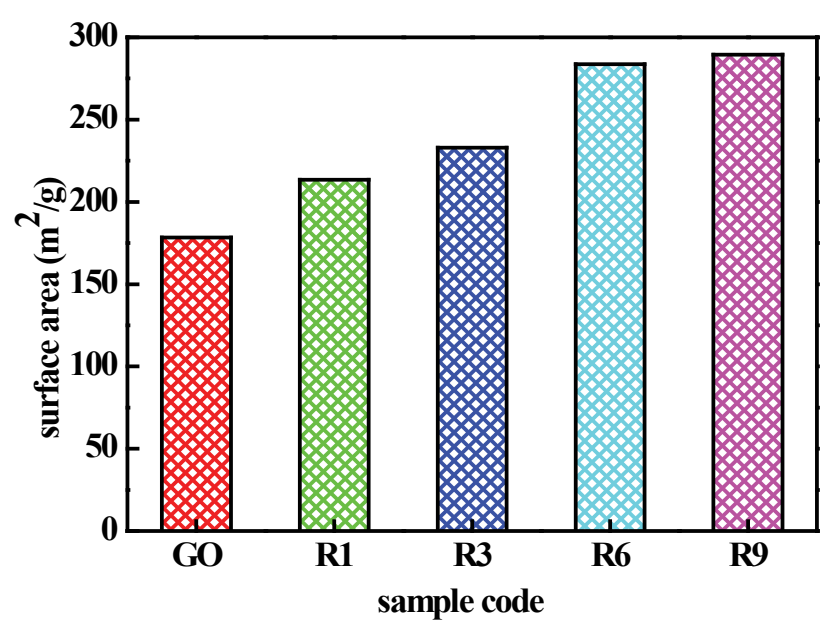

Figure 8: Specific surface area of GO and garphene samples. 


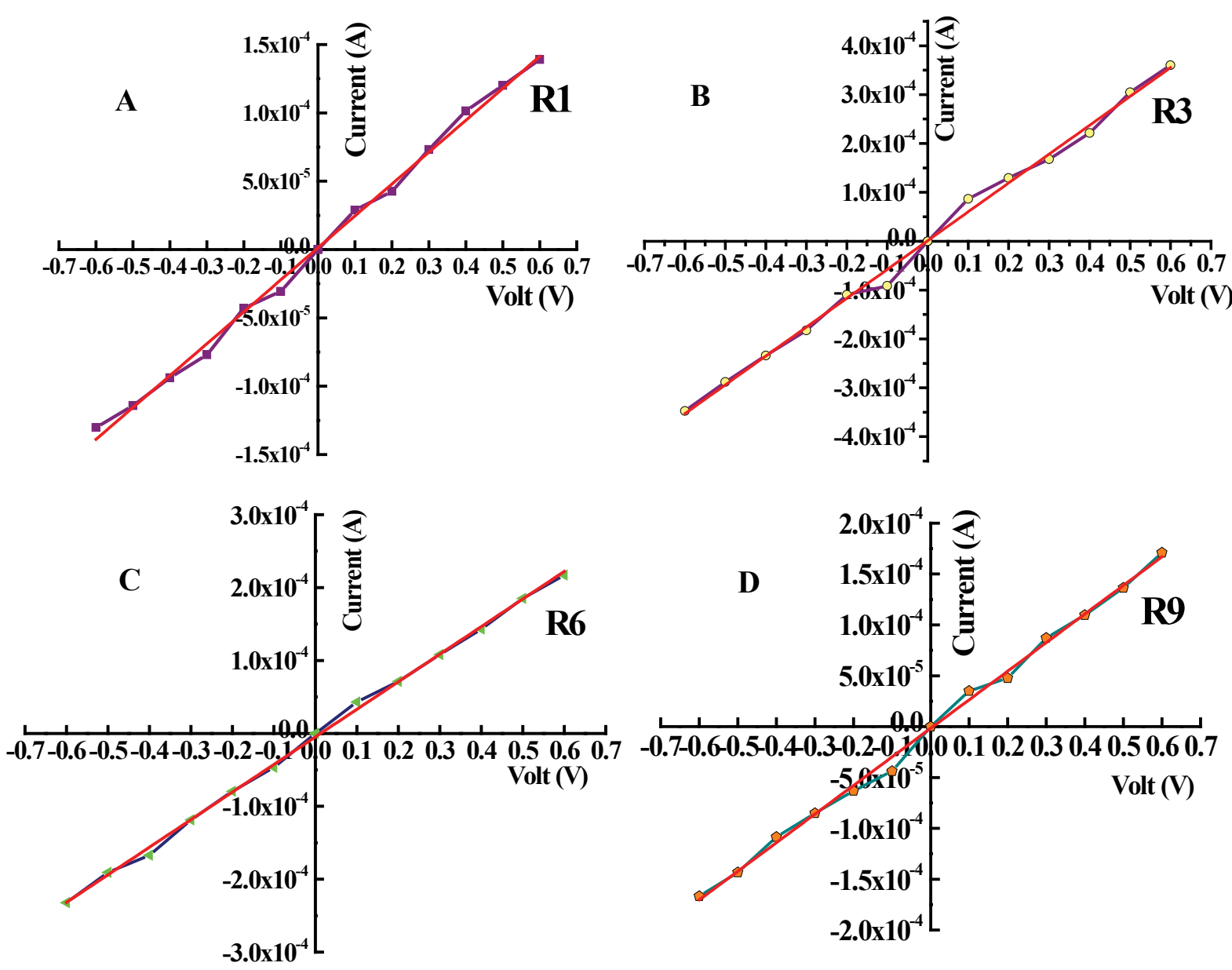

Figure 9: I-V characteristic curves of A) R1; B) R3; C) R6 and D) R9 samples.

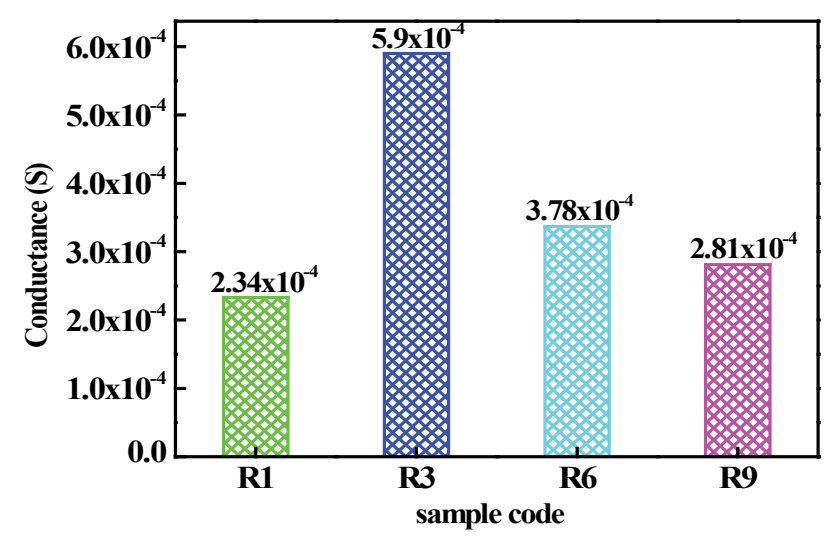

Figure 10: Electric conductance of R1, R3, R6 and R9 samples.

for GO, R1, R3, R6 and R9, respectively, with improvement ratios of about $19.67,30.61,58.97$ and $62.28 \%$ for R1, R3, R6 and $\mathrm{R} 9$ with respect to GO, respectively.

It is clear that the increased reduction time significantly increased the surface area of the prepared graphene samples, this in turn reflects on the reactivity of the samples, but a single layer graphene still has much higher surface area $\left(2630 \mathrm{~m}^{2} / \mathrm{g}\right)$ [42], this means that our samples composed of few graphene layers.

\section{Electrical conductivity}

Figure 9 show the I-V characteristic curves obtained for R1, R3, R6 and R9 respectively, while Figure 10 shows the electric conductance of graphene samples obtained as described in section (3.7). Conductivity of GO depends on the extent of oxidation. While oxidation, we were continuously removing the $\mathrm{sp}^{2}$ carbons and replacing it by $\mathrm{sp}^{3}$ carbons having oxygen functionalities. In essence, you are creating a band gap by pulling the bands apart. Hence when oxidation was completed, the bands are far apart and GO behaves as an insulator. It is clear that the conductivity of graphene increased as reduction time was increased up to 3 hours then, a gradual decrease in conductivity was observed for R6 and R9, where, the enhancement reached about 152.72, 62 and 20.39 for R3, R6 and R9 with respect to R1, respectively.

\section{Conclusions}

The influence of increasing reduction time on the microstructural characteristics, surface area, thermal stability and electrical properties of graphene sheets was investigated in this study. The results revealed that: 
- GO platelets were will exfoliated and reduced to graphene sheets by increased reduction time to 9 hours as confirmed by TEM, FTIR and XRD analysis, hence, GO peak was disappeared from XRD pattern for $\mathrm{R}$ samples, also the $\mathrm{d}$-spacing of graphene was $3.51 \AA$ that was very close to that of graphite.

- Thermal stability of GO was increased after thermal reduction for only an hour, which is useful for battery applications then, decreased at higher reduction times.

- Increasing the reduction time, gave a high quality of graphitization, where $\mathrm{I}_{\mathrm{D}} / \mathrm{I}_{\mathrm{G}}$ ratio reached 1.34 as observed in Raman spectra.

- The surface area was highly improved by about $62.28 \%$ for R9 in comparison with GO.

- Finally, electrical conductivity was markedly enhanced by about $152.72 \%$ for R3 in comparison with $\mathrm{R} 1$ then showed gradually decreasing.

\section{Acknowledgement}

Authors are gratefully acknowledged Housing and Building Research Center (HBRC), Physics department of Al Azhar University, Dr. Mohamed Morsy (HBRC) for their help in performing this work.

\section{References}

1. Hao Tong, Jiajia Zhu, Jianhui Chen, Yongqin Han, Sudong Yang, et al. (2013) Electrochemical reduction of graphene oxide and its electrochemical capacitive performance. $\mathrm{J}$ Solid State Electrochem 17: 2857-2863.

2. DP Hansora, NG Shimpi, S Mishra (2015) Graphite to Graphene via Graphene Oxide: An Overview on Synthesis, Properties, and Applications. JOM 67: 2855-2868.

3. H Raza (2012) Graphene Nanoelectronics. 15: 586.

4. AK Geim, KS Novoselov (2007) The rise of graphene. Nat Mater 6: 183-191.

5. T Kuilla, S Bhadra, D Yaoa, NH Kim, S Bose, et al. (2010) Recent advances in graphene based polymer composites Prog. Polym Sci 35: 1350-1375.

6. CNR Rao, AK Sood, KS Subrahmanyam, A Govindara (2009) Graphene: the new two-dimensional nanomaterial. Angew Chem Int 48: 7752-7777.

7. Jeffrey R Potts, Shanthi Murali, Yanwu Zhu, Xin Zhao, Rodney S Ruoff (2011) Microwave-Exfoliated Graphite Oxide/ Polycarbonate Composites. Macromolecules 44: 6488-6495.

8. SA El Khodary, GM El Enany, M El Okr, M Ibrahim (2014) Preparation and characterization of microwave reduced graphite oxide for high-performance super capacitors. Electrochim Acta 150: 269-278.

9. Kai Gong, SM ASCE, Zhu Pan, Asghar H Korayem, Ling Qiu, et al. (2015) Reinforcing Effects of Graphene Oxideon Portland Cement Paste. J Mater Civ Eng 27.

10. Qin Wang, Jian Wang, Chun xiang Lu, Bo wei Liu, Kun Zhang, et al. (2015) Influence of graphene oxide additions on the microstructure and mechanical strength of cement. New Carbon Materials 30: 349-356.

11. Hongjian Du, Sze Dai Pang (2015) Mechanical Response and Strain Sensing of Cement Composites Added with Graphene Nanoplatelet Under Tension. Nanotechnology in Construction 377-382.

12. Mohamed Saafi, Leung Tang, Jason Fung, Mahbubur Rahman, John Liggat (2015) Enhanced properties of graphene/ fly ash geopolymeric composite cement. Cement and Concrete Research 67: 292-299.

13. Sze Dai Pang, Hongchen Jacey Gao, Chunying $\mathrm{Xu}$, Ser Tong Quek, Hongjian Du (2014) Strain and damage self-sensing cement composites with conductive graphene nanoplatelet. Sensors and Smart Structures Technologies for Civil, Mechanical, and Aerospace Systems.

14. Radhika Pavgi, Zhangfan Jiang, Andrei Ramniceanu, Osman E Ozbulut, Devin K Harris (2016) Self-Sensing Cementitious Composites With Graphene Nanoplatelets. International Concrete Sustainability Conference May 15-18, Washington, DC.

15. Wonjun Park, Jiuning Hu, Luis A Jauregui, Xiulin Ruan, Yong P Chen (2014) Electrical and thermal conductivities of reduced graphenexide/polystyrene composites. Appl Phys Lett 104: 113101.

16. Jun Liu, Yuhua Xue, Mei Zhang, Liming Dai (2012) Graphene-based materials for energy applications. Materials Research Society 37: 1265-1272.

17. Leila shahriary, Anjali A Athawale (2014) Graphene Oxide Synthesized by using Modified Hummers Approach. International Journal of Renewable Energy and Environmental Engineering 2: 58-63.

18. Claire Berger, Zhimin Song, Tianbo Li, Xuebin Li, Asmerom Y Ogbazghi, et al. (2004) Ultra thin epitaxial graphite: 2D electron gas properties and a route toward graphene-based nanoelectronics. J Phys Chem 108: 19912-19916.

19. Zhong li Wang, Dan Xu, Yun Huang, Zhong Wu, Li min Wang, et al. (2011) Facile, mild and fast thermal-decomposition reduction ofgraphene oxide in air and its application in high-performance lithium batteries. Electronic Supplementary Material (ESI) for Chemical Communications.

20. Zheng, Qingbin, Kim, Jang Kyo (2015) Graphene for Transparent Conductors Synthesis, Properties and applications. Synthesis, Structure, and Properties of Graphene and Graphene Oxide, Springer.

21. Nils Krane (2011) Preparation of Graphene Selected Topics in Physics: Physics of Nanoscale Carbon.

22. Ming Zhou, Tian Tian, Xuanfu Li, Xudong Sun, Juan Zhang, et al. (2014) Production of Graphene by Liquid-Phase Exfoliation of Intercalated Graphite. Int J Electrochem Sci 9: 810-820.

23. JJ Wang, MY Zhu, RA Outlaw, X Zhao, DM Manos, et al. (2004) Free-standing subnanometer graphite sheets. Appl Phys Lett 85: 1265.

24. J Wang, M Zhu, RA Outlaw, X Zhao, DM Manos, et al. (2004) synthesis of carbon nanosheets by inductively coupled radio-frequency plasma enhanced chemical vapour deposition. Carbon 42: 2867-2872.

25. CNR Rao, KS Subrahmanyam, HSS Ramakrishna Matte, B Abdulhakeem, A Govindaraj, et al. (2010) A study of the 
synthetic methods and properties of graphenes. Sci Technol Adv Mater 11: 054502.

26. Pati SK, Enoki T, Rao CNR (2010) Graphene and its Fascinating Attributes. World Scientific Publishing Co Chennai.

27. CNR Rao, Urmimala Maitra, HSS Ramakrishna Matte (2013) Synthesis, Characterization, and Selected Properties of Graphene. Wiley Online Library.

28. W Zhiyong, L Nan, S Zujin, G Zhennan (2010) Low-cost and large-scale synthesis of graphenenanosheets by arc discharge in air. Nanotechnology 21: 175602.

29. MM Mokhtar, SA Abo El Enein, MY Hassaan, MS Morsy, MH Khalil (2017) Mechanical performance, pore structure and micro-structural characteristics of graphene oxide nano platelets reinforced cement. Construction and Building Materials 138: 333-339.

30. M Morsy (2016) Preparation and characterization of carbon nano based materials as gas sensor. Azhar University, Giza, Egypt.

31. J Yang, M Wu, F Chen, Z Fei, M Zhong (2011) Preparation, characterization, and supercritical carbon dioxide foaming of polystyrene/graphene oxide composites. J Supercrit Fluids 56: 201-207.

32. Fatima Tuz Johra, Jee Wook Lee, Woo Gwang Jung (2014) Facile and safe graphene preparation on solution based platform. Journal of Industrial and Engineering Chemistry 20: 2883-2887.

33. Peng Cui, Junghyun Lee, Eunhee Hwang, Hyoyoung Lee (2011) One-pot reduction of graphene oxide at subzero temperatures. Chem Commun 47: 12370-12372.
34. HK Jeong, MH Jin, KP So, SC Lim, YH Lee (2009) Tailoring the characteristics of graphite oxides by different oxidation times. J Phys D: Appl Phys 42: 65418.

35. CC Wang, CC Hu (2005) Electrochemical catalytic modification of activated carbon fabrics by ruthenium chloride for supercapacitors. Carbon 43: 1926-1935.

36. Z Lei, L Lu, XS Zhao (2012) The electrocapacitive properties of graphene oxidereduced by urea. Energy Environ Sci 5: 6391-6399.

37. L Tang, Y Wang, Y Li, H Feng, J Lu, et al. (2009) Preparation, structure, and electrochemical properties of reduced graphene sheet films. Adv Funct Mater 19: 2782-2789.

38. Mahesh Shantaram Patil (2013) Ultrasound-Assisted Desulfurization of Commercial Kerosene by Adsorption. J Chem Eng Process Technol 4.

39. Rungang Gao, Nantao Hu, Zhi Yang, Qirong Zhu, Jing Chai, et al. (2013) Paper-like graphene-Ag composite films withenhanced mechanical and electrical properties. Nanoscale Research Letters 8.

40. AC Ferrari, JC Meyer, V Scardaci, C Casiraghi, M Lazzeri, et al. (2006) Raman Spectrum of Graphene and Graphene Layers. Phys Rev Lett 97: 187401.

41. Sreekanth Perumbilavil, Pranitha Sankar, T Priya Rose, Reji Philip (2015) White light Z-scan measurements of ultrafast optical nonlinearity in reduced grapheneoxide nanosheets in the $400-700 \mathrm{~nm}$ region. Applied Physics Letters 107: 051104.

42. SY Yang, KH Chang, HW Tien, YF Lee, SM Li, et al. (2011) Design and tailoring of a hierarchical graphene-carbon nanotube architecture for super capacitors. J Mater Chem 21: 2374-2380. 